\title{
Heterogeneity of perception of symptoms in patients with asthma
}

\author{
Akihiko Ohwada ${ }^{1,2}$, Katsuhiko Sato ${ }^{3}$ \\ ${ }^{1}$ Ohwada Clinic, Chiba-ken, Japan; ${ }^{2}$ Division of Respiratory Medicine, Juntendo University Faculty of Medicine and Graduate School of Medicine, \\ Tokyo, Japan; ${ }^{3}$ Occupational Health Consultant Office, Hyougo-ken, Japan \\ Contributions: (I) Conception and design: All authors; (II) Administrative support: None; (III) Provision of study materials or patients: None; (IV) \\ Collection and assembly of data: None; (V) Data analysis and interpretation: All authors; (VI) Manuscript writing: All authors; (VII) Final approval of \\ manuscript: All authors. \\ Correspondence to: Akihiko Ohwada. Ohwada Clinic, 4-7-13 Minamiyawata, Ichikawa, Chiba-ken 272-0023, Japan. Email: aohwadac@gmail.com.
}

Background: Cough-dominant or cough-variant asthma is common in Japan. However, it is unclear whether cough and dyspnea, the cardinal symptoms of bronchial asthma, are similarly perceived, and whether these symptoms are linked to pulmonary function tests.

Methods: The subjects were 548 physician-diagnosed naive patients with asthma. Visual analogue scale (VAS) scores were determined and spirometry was performed before and after 1-month inhaled corticosteroid/long-acting beta2 agonist therapy.

Results: The patients were divided into those with a significant bronchodilating response and an increase in $\mathrm{FEV}_{1}(>12 \%$ and $>200 \mathrm{~mL})$ after treatment $(\mathrm{n}=146)$; and nonresponders without this response $(\mathrm{n}=402)$. Cough was more dominant than dyspnea in both groups at the initial evaluation. Both symptoms were diminished after treatment, but scores for cough remained significantly higher than those for dyspnea in nonresponders. VAS scores for dyspnea at both time points differed in responders and nonresponders, and changes of cough and dyspnea scores were larger in responders. In responders, peak expiratory flow (PEF) (absolute, \% predicted) for cough and $\mathrm{FEV}_{1}$ (\% predicted), VC (\%predicted) and PEF (absolute) for dyspnea were correlated at both time points, but in nonresponders, neither cough nor dyspnea was related to a common spirometric parameter at both time points. Changes in cough and dyspnea scores were correlated with changes of $\mathrm{FEV}_{1}$ (absolute, \% predicted) and $\mathrm{FEF}_{25-75}$ (absolute) for responders, while only PEF (\%predicted) was correlated with these changes in nonresponders. Calculated slopes ( $\left.\triangle \mathrm{VAS} \operatorname{score} / \Delta \mathrm{FEV}{ }_{1}\right)$ suggested that responders were more sensitive to dyspnea than nonresponders.

Conclusions: Perception of cough and dyspnea were similar, but not identical, for bronchodilating responders and nonresponders among patients with bronchial asthma. Linkage of pulmonary function parameters with perceptions of cough and dyspnea also differed between the responders and nonresponders.

Keywords: Perception; dyspnea; cough; visual analogue scale (VAS); bronchial asthma

Submitted May 09, 2019. Accepted for publication Oct 23, 2019.

doi: $10.21037 /$ jtd.2019.11.72

View this article at: http://dx.doi.org/10.21037/jtd.2019.11.72

\section{Introduction}

In a population-based survey of patients with asthma, the symptom rates were $7.8 \%$ for wheezing, $6.6 \%$ for cough, $6 \%$ for chest tightness, and $3.6 \%$ for dyspnea or shortness of breath (1). In Japan, cough is prominent, and the incidence of cough-dominant or cough-variant asthma is high (2). A preliminary evaluation in our clinic also showed that cough and dyspnea were cardinal symptoms in patients with bronchial asthma, and that patients subjectively evaluated the disease activity mainly through their perception of these symptoms (3). Recent evaluations using the asthma control questionnaire (ACQ) (4) and asthma control test (ACT) (5) suggest that these symptoms are pivotal in judgment of asthma control. However, defective perception of dyspnea in a patient with bronchial asthma has also been 
pointed out, and this may lead to under-treatment and result in greater morbidity and mortality from asthma (6).

In the real clinical setting, many patients discontinue use of inhaled corticosteroids (ICS) or ICS/long-acting beta2 agonist (LABA) treatment after symptoms diminish or disappear, even if physicians explain the future risk (3). Furthermore, we are always concerned whether the perception of symptoms is reliable. A visual analogue scale (VAS) is a useful tool to quantify the severity of symptoms in adults or children with bronchial asthma $(7,8)$. In this study, we evaluated whether perception of symptoms, in particular cough and dyspnea, in patients with bronchial asthma before and after ICS/LABA treatment are similar and can be used to judge the status of asthma control. We also examined the relationships of perceived symptoms with pulmonary function.

\section{Methods}

\section{Selection of patients}

The subjects were patients who were diagnosed with bronchial asthma who made their first visit to our clinic in August 2014 to July 2015 and were treatment-naive or had not taken ICS, short-acting $\beta 2$ agonists (SABAs) or LABAs for at least 3 months before the first evaluation. VAS scores for cough and dyspnea and spirometry data were obtained at the first visit (baseline). The patients were asked to visit as soon as possible after 1-month ICS/LABA treatment (fluticasone propionate/salmeterol at 250/50 $\mu \mathrm{g}$ twice a day or budesonide/formoterol at 160/4.5 $\mu \mathrm{g}$ twice a day) for a second evaluation of VAS and spirometry. Patients whose second visit was more than 3 months from the baseline evaluation were excluded from the study.

\section{VAS}

The VAS scale is a horizontal line $(100 \mathrm{~mm})$ labeled with "no symptom" on the left $(0 \mathrm{~mm})$ to "most extreme symptom ever experienced" on the right $(100 \mathrm{~mm})$. The patient was asked to indicate scores for cough and dyspnea perceived in one week prior to the baseline evaluation or since the symptoms appeared in cases with symptoms lasting less than 1 week before the evaluation. At the evaluation after treatment, VAS scores were obtained for the 1 week before the evaluation. The patients did not know the results of spirometry before completing the VAS scores.

\section{Spirometry}

Spirometry was conducted with a Microspiro HI-801 (Nihon Koden-Chest Inc., Japan) following instructions in the ATS/ERS guidelines, and the highest FVC, VC, $\mathrm{FEV}_{1}$, and $\mathrm{FEV}_{1} / \mathrm{FVC}$ ratio were taken (9). For $\mathrm{FEV}_{1}, \mathrm{VC}, \mathrm{FVC}$, and $\mathrm{FEV}_{1} / \mathrm{FVC}$ ratio, the spirometric reference values were calculated from equations using the LMS methods for Japanese patients (10). The peak expiratory flow (PEF), forced expiratory flow at $50 \%$ of vital capacity expired $\left(\mathrm{FEF}_{50}\right)$, forced expiratory flow at $75 \%$ of vital capacity expired $\left(\mathrm{FEF}_{75}\right)$, and forced expiratory flow between $25 \%$ and $75 \%$ of $\mathrm{VC}\left(\mathrm{FEF}_{25-75}\right)$ were measured. These parameters are presented as absolute values and percent predicted values (\% predicted) $(11,12)$. A significant bronchodilating response was defined as an increase in $\mathrm{FEV}_{1}$ of $>12 \%$ and $>200 \mathrm{~mL}$ after 1 -month ICS/LABA treatment compared with the baseline evaluation (13). Patients with and without this response were defined as responders and nonresponders, respectively.

\section{$\triangle V A S$ score/AFEV}

Linear regression analysis was used to evaluate the perception of symptoms between responders and nonresponders (14-19). The slope ( $\triangle \mathrm{VAS}$ score/ $\triangle \mathrm{FEV}_{1}$ ) was calculated using the change of $\mathrm{FEV}_{1}$ expressed as a percentage of the initial value (independent variable, $\mathrm{X}$-axis) and the absolute change in each VAS score (dependent variable, Y-axis). This slope indicates perception of cough or dyspnea for each group, and not for individuals of each group. All patients provided informed consent and the study was approved by the institutional review board.

\section{Data analysis}

Quantitative variables are shown as medians with an interquartile range (IQR). Correlation coefficients between VAS scores and absolute values of lung function tests at each evaluation and between changes of VAS scores and changes of spirometric parameters were evaluated using the nonparametric Spearman method. VAS scores for cough and dyspnea and spirometric parameters were compared between responders and nonresponders by nonparametric paired $t$-test. All analyses were performed using Graphpad Prism ver. 6 (Graphpad Software, Inc, San Diego, CA, USA), with $\mathrm{P}<0.05$ considered to indicate a significant 
difference.

\section{Results}

Of 1,325 potential subjects, 548 patients were enrolled in the study using the selection criteria. The incidences of respiratory symptoms at the initial evaluation (baseline) were cough $87.9 \%$; dyspnea $42.0 \%$; phlegm $34.0 \%$; wheezing $6.7 \%$; and chest tightness $2.4 \%$. Cough was prominent in our study population, consistent with our preliminary study and other studies in Japanese subjects (2). The incidence of wheezing was low, as we have previously noted (9). All patients had mild to moderate bronchial asthma (20). There were 146 bronchodilating responders (26.6\%) and 402 nonresponders (73.4\%) among the 548 patients. The characteristics of the two groups are shown in Table 1 .

\section{Comparison between VAS scores for cough and dyspnea}

At baseline, VAS scores [median (25th to 75 th IQR)] for cough were significantly higher than those for dyspnea in responders [68.3 (49.6 to 82) vs. 54.0 (27.6 to 70.9), $\mathrm{P}<0.0001]$ and non-responders [66.7 (42.0 to 79.9) vs. 45.5 (18.3 to 62.7), $\mathrm{P}<0.001$ ] (Figure 1 ). Thus, both groups perceived that cough was more severe than dyspnea at baseline. After ICS/LABA treatment, VAS scores for cough were similar to those for dyspnea in responders [13.8 (2.5 to 35.9 ) vs. 10.6 (10.6 to 24.9$), \mathrm{P}=0.1518$ ], and were also decreased, but still significantly higher than those for dyspnea, in nonresponders [19.9 (7.0 to 37.0) vs. 15.1 (1.4 to 38.5), $\mathrm{P}=0.0259]$.

\section{Comparison of responders and nonresponders}

VAS scores for cough were similar in responders and nonresponders at baseline $(\mathrm{P}=0.0814)$, but significantly lower in responders than in nonresponders after treatment $(\mathrm{P}=0.0177)$. VAS scores for dyspnea at baseline were significantly higher in responders $(\mathrm{P}=0.0055)$, but after treatment these scores were significantly lower in responders than in non-responders $(\mathrm{P}=0.0417)$. The changes in VAS scores for cough [47.8 (19.1 to 66.2) vs. 35.1 (8.0 to 58.2), $\mathrm{P}=0.0029]$ and dyspnea [30.2 (6.5 to 53.4) vs. 15.0 (0 to 38.9 ), $\mathrm{P}<0.0001]$ were also larger in responders than in nonresponders. These comparisons suggest that perceptions of cough and dyspnea had some similarities, but were not identical, in responders and nonresponders.
Improvement of dyspnea after the treatment was observed in 123 (84.2\%) of 146 responders and in 290 (72.1\%) of 402 non-responders, respectively ( $\mathrm{P}=0.0037$, data not shown). The alleviation of cough after the treatment was also obtained in 128 (87.7\%) among 146 responders and 329 (81.8\%) among 402 non-responders ( $\mathrm{P}=0.1053$, data not shown). In other hand, neither dyspnea nor cough improvement was observed only in $9(6.2 \%)$ of 146 responders and $35(8.7 \%)$ of 402 non-responders $(\mathrm{P}=0.3338$, data not shown). These results suggested rate of improvement of symptoms between responders and nonresponders were almost similar after the treatment, although there was a different in degree for the amelioration of dyspnea with statistical difference.

\section{VAS scores for symptoms and pulmonary function}

Next, we evaluated the relationships of VAS scores for symptoms with pulmonary function parameters (Table 2). In responders, VAS scores for cough at baseline were significantly correlated with VC (absolute, \% predicted) and PEF (absolute, \%predicted) and those after treatment were correlated with $\mathrm{FEV}_{1}$ (absolute, \% predicted), FVC (absolute, \% predicted), PEF (absolute, \% predicted), and $\mathrm{FEF}_{50}$ (absolute). Thus, PEF (absolute, \% predicted) was the only spirometric parameter that was correlated with VAS scores for cough in responders before and after treatment. VAS scores for dyspnea in responders at baseline were correlated with $\mathrm{FEV}_{1}$ (\% predicted), VC (absolute, \% predicted), PEF (absolute), and $\mathrm{FEF}_{25-75}$ (\% predicted) (Table 2), and these scores after treatment were correlated with $\mathrm{FEV}_{1}$ (absolute, \% predicted), VC (\% predicted), FVC (absolute, \% predicted), and PEF (absolute, \% predicted). Thus, VAS scores for dyspnea before and after treatment were related to $\mathrm{FEV}_{1}$ (\% predicted), VC (\% predicted) and PEF (absolute).

In nonresponders, VAS scores for cough at baseline were significantly correlated with $\mathrm{FEF}_{75}$ (absolute) (Table 2), and these scores after treatment were correlated with $\mathrm{FEV}_{1}$ (\% predicted), VC (\% predicted), FVC (\%predicted) and PEF (\% predicted). VAS scores for dyspnea in nonresponders at baseline were significantly related to $\mathrm{FEV}_{1} / \mathrm{FVC}$ ratio and $\mathrm{FEF}_{75}$ (absolute), and these scores after treatment were correlated with $\mathrm{FEV}_{1}$ (\% predicted), VC (\% predicted), FVC (\% predicted), PEF (absolute, \% predicted), $\mathrm{FEF}_{50}$ (\% predicted), and $\mathrm{FEF}_{25-75}$ (\% predicted).

Correlations of changes $(\Delta)$ in VAS scores for symptoms with changes of absolute and \%predicted spirometric 
Table 1 Characteristics of responders and non-responders

\begin{tabular}{|c|c|c|c|}
\hline Item & Responders & Non-responders & $\mathrm{P}$ \\
\hline Age (years) & $39(31-52.8)$ & 39 [31-46] & 0.461 \\
\hline Gender (female:male) & $102: 44: 00$ & $246: 156$ & 0.0558 \\
\hline Interval between evaluations (days) & 34 [28-43] & 33 [28-43] & 0.5002 \\
\hline \multicolumn{4}{|l|}{$\mathrm{FEV}_{1}$ absolute } \\
\hline Baseline & $2.10(1.69-2.46)$ & $2.73(2.31-3.28)$ & $<0.0001$ \\
\hline After treatment & 2.67 (2.29-3.09) & 2.76 (3.37-2.32) & 0.138 \\
\hline$\Delta$ & $0.54(0.35-0.69)$ & $0.06(-0.04-0.16)$ & $<0.0001$ \\
\hline After treatment & 96 [86-105] & 95 [86-103] & 0.8019 \\
\hline$\Delta$ & $18.56(12.55-25.25)$ & $1.95(-1.54-5.55)$ & $<0.0001$ \\
\hline \multicolumn{4}{|l|}{ VC absolute } \\
\hline Baseline & $2.61(2.20-3.24)$ & $3.17(2.59-3.86)$ & $<0.0001$ \\
\hline After treatment & $3.30(2.56-3.63)$ & $3.17(2.63-3.93)$ & 0.0752 \\
\hline$\Delta$ & $0.37(0.12-0.67)$ & $0.03(-0.21-0.28)$ & $<0.0001$ \\
\hline \multicolumn{4}{|l|}{ VC \%predicted } \\
\hline Baseline & 77 (67-89) & $88(78-99)$ & $<0.0001$ \\
\hline$\Delta$ & $0.32(0.17-0.55)$ & $0.02(-0.10-0.13)$ & $<0.001$ \\
\hline \multicolumn{4}{|l|}{ FVC \%predicted } \\
\hline Baseline & $84(75-96)$ & $94(87-103)$ & $<0.0001$ \\
\hline After treatment & $95(88-107)$ & $95(86-103)$ & 0.2397 \\
\hline$\Delta$ & $10.11(-5.54-15.90)$ & $0.50(-2.82-3.72)$ & $<0.0001$ \\
\hline \multicolumn{4}{|l|}{$\mathrm{FEV}_{1} / \mathrm{FVC}$ ratio } \\
\hline Baseline & $0.76(0.67-0.81)$ & $0.83(0.79-0.87)$ & $<0.0001$ \\
\hline After treatment & $0.84(0.78-0.88)$ & $0.84(0.80-0.89)$ & 0.1603 \\
\hline$\Delta$ & $7.11(3.42-13.00)$ & $1.13(-0.56-3.17)$ & $<0.0001$ \\
\hline \multicolumn{4}{|l|}{ PEF absolute } \\
\hline Baseline & $4.21(3.27-5.13)$ & $5.64(4.45-7.10)$ & $<0.0001$ \\
\hline
\end{tabular}

Table 1 (continued) 
Table 1 (continued)

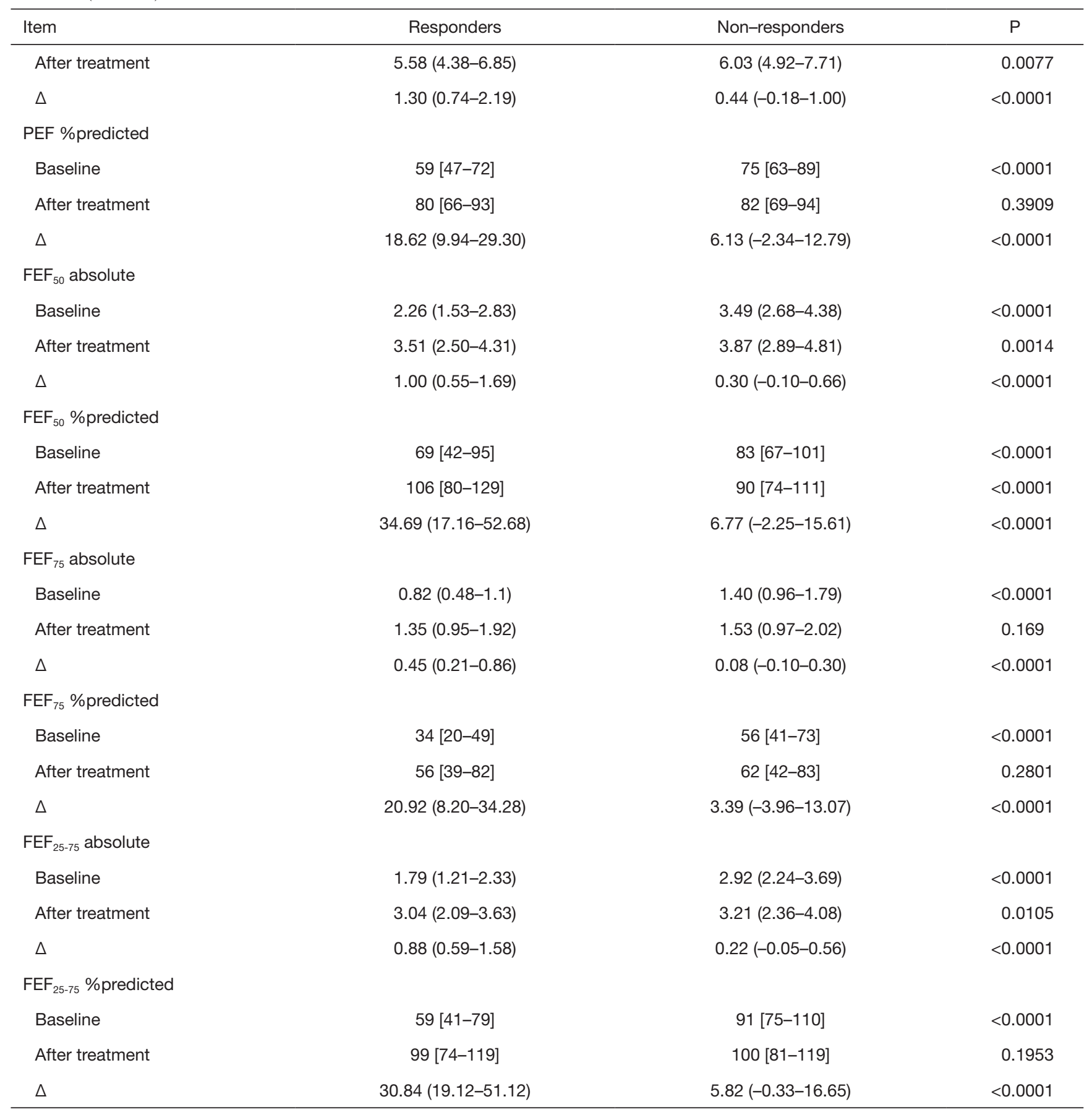

Values are median (25th-75th IQR). $\Delta$, indicates changes after treatment from baselines. NS, never smoked; ES, ex-smoker who has quit for at least 3 years; SM, smoker. 

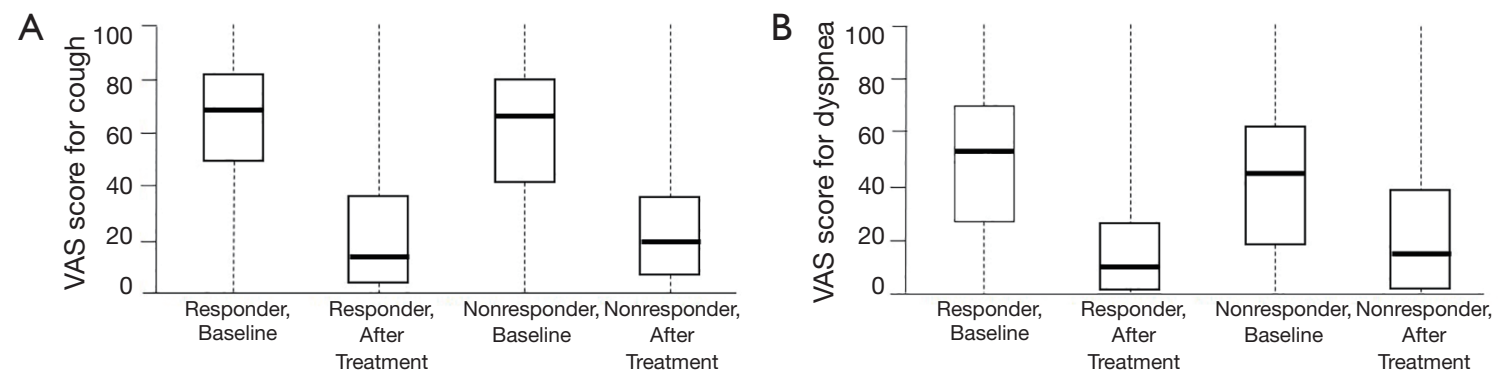

Figure 1 VAS scores for cough and dyspnea. VAS scores for cough (upper panel) and dyspnea (lower panel) are shown at baseline and after one-month ICS/LABA treatment in bronchodilating responders and non-responders. Perceptions of cough were similar between the responders and non-responders at baseline, but improved more in responders after treatment. Perception of dyspnea was severer in responders at baseline and relief from dyspnea was greater in responders after treatment. Perpendicular dotted lines indicate maximum and minimum values. VAS, visual analogue scale; ICS, inhaled corticosteroids; LABA, long-acting beta2 agonist.

parameters from baseline to after treatment were also evaluated (Tables 1,3). In responders, $\triangle$ VAS for cough was significantly correlated with $\triangle \mathrm{FEV}_{1}$ (absolute, \% predicted), $\triangle \mathrm{FEV}_{1} / \mathrm{FVC}$ ratio, $\Delta \mathrm{FEF}_{50}$ (absolute, \% predicted), $\Delta \mathrm{FEF}_{75}$ (\%predicted), and $\triangle \mathrm{FEF}_{25-75}$ (absolute, \% predicted), and $\triangle \mathrm{VAS}$ for dyspnea was correlated with $\triangle \mathrm{FEV}_{1}$ (absolute, $\%$ predicted), $\triangle \mathrm{VC}$ (\% predicted), $\triangle \mathrm{FVC}$ (absolute, $\%$ predicted), and $\triangle \mathrm{FEF}_{25-75}$ (absolute). In nonresponders, $\triangle$ VAS for cough was correlated with $\triangle \mathrm{PEF}$ (absolute, $\%$ predicted), and $\triangle$ VAS for dyspnea was significantly correlated with $\triangle \mathrm{PEF}$ (\%predicted) and $\triangle \mathrm{FEF}_{50}$ (\% predicted).

\section{$\triangle V A S$ score/ $\triangle F E V_{1}$}

To compare perceptions of responder and nonresponders, the slope ( $\triangle \mathrm{VAS}$ score/ $\Delta \mathrm{FEV}_{1}$ ) was calculated. For cough, the slopes were 0.32 for responders and 0.31 for the nonresponders. In contrast, for dyspnea, the respective slopes were 0.38 and 0.15 . A smaller slope indicates lower sensitivity. Therefore, the perception of cough was similar in responders and nonresponders, whereas responders seemed to be more sensitive or nonresponders may be less sensitive to dyspnea.

\section{Discussion}

The bronchodilating response is commonly evaluated using a SABA, but a bronchodilating effect in a real clinical setting is mainly induced with ICS/LABA therapy. Moreover, improvement of $\mathrm{FEV}_{1}$ with 1-month ICS/LABA treatment was better than that with a SABA in our previous study (9).
In the GINA guidelines, a bronchodilating response is defined as an increase in $\mathrm{FEV}_{1}$ by $>12 \%$ and $>200 \mathrm{~mL}$ from baseline after 4 weeks of treatment (11). Hence, we used this definition in evaluation of patients after ICS/LABA therapy.

There will be skeptics about nonresponders, based on the opinion that patients with bronchial asthma are necessary to demonstrate a significant change in airway obstruction either spontaneously or following the treatment. In fact, 402 patients (73.4\%) among 548 nonresponders in this study seemed to show no change in airway obstruction following 1-month ICS/LABA treatment. However, this criticism may be not suitable. First, Yancey et al. indicated the rate of airway reversibility according to the percent predicted $\mathrm{FEV}_{1}$ values from a total of 30,816 patients in 106 clinical trials (21). From their observations, patients with a baseline $\mathrm{FEV}_{1}$ (\% predicted) values between $\geq 40 \%$ and $>50 \%, \geq 50 \%$ and $<60 \%, \geq 60 \%$ and $<70 \%, \geq 70 \%$ and $<80 \%, \geq 70 \%$ and $<80 \%, \geq 80 \%$ and $<90 \%, \geq 90 \%$ and $<100 \%$ showed $42.14 \%$, $34.09 \%, 27.57 \%, 22.68 \%, 19.43 \%, 18.33 \%$ of airway reversibility, respectively. In conclusion, patients with better $\mathrm{FEV}_{1}$ have less airway reversibility. In our study, overall $\%$ predicted $\mathrm{FEV}_{1}$ value in total 548 patients were $87 \%(76 \%$ to $97 \%$ ) [median (25th to 75 th IQR), data not shown] and rate of reversibility was $26.6 \%$, not far apart from Yancey's presentation. Secondly, this study divided the patients into responder and nonresponders. However, nonresponders in this study did not mean having no responsiveness to the treatment. Improvement rate of dyspnea and cough after ICS/LABA therapy in nonresponders was $72.1 \%$ and $81.8 \%$, respectively (see in Results). In addition, "true" nonresponders without any improvement of dyspnea or 
Table 2 Correlations between asthma symptoms and lung function parameters

\begin{tabular}{|c|c|c|c|c|c|}
\hline Subjects & Evaluation & Symptom & Parameter & r & $\mathrm{P}$ \\
\hline \multirow{3}{*}{ Responders } & & & VC \%predicted & -0.172 & 0.0379 \\
\hline & & & PEF absolute & -0.1786 & 0.031 \\
\hline & & & PEF \%predicted & -0.1746 & 0.0351 \\
\hline \multirow{4}{*}{ Responders } & & & FVC absolute & -0.2184 & 0.0081 \\
\hline & & & FVC \%predicted & -0.2246 & 0.0064 \\
\hline & & & PEF absolute & -0.2426 & 0.0032 \\
\hline & & & PEF \%predicted & -0.212 & 0.0102 \\
\hline \multirow{4}{*}{ Responders } & & & VC absolute & -0.1676 & 0.0432 \\
\hline & & & VC \%predicted & -0.1858 & 0.0248 \\
\hline & & & PEF absolute & -0.1814 & 0.0284 \\
\hline & & & $\mathrm{FEF}_{25-75} \%$ predicted & -0.2134 & 0.0097 \\
\hline \multirow[t]{4}{*}{ Responders } & After treatment & Dyspnea vs. & $\mathrm{FEV}_{1}$ absolute & -0.1936 & 0.0192 \\
\hline & & & $\mathrm{FEV}_{1} \%$ predicted & -0.2718 & 0.0009 \\
\hline & & & VC \%predicted & -0.2257 & 0.0062 \\
\hline & & & FVC absolute & -0.1728 & 0.037 \\
\hline \multirow{3}{*}{ Nonresponders } & & & VC \%predicted & -0.1639 & 0.001 \\
\hline & & & FVC \%predicted & -0.1994 & $<0.0001$ \\
\hline & & & PEF \%predicted & -0.1079 & 0.0306 \\
\hline \multirow[t]{2}{*}{ Nonresponders } & Baseline & Dyspnea vs. & $\mathrm{FEV}_{1} / \mathrm{FVC}$ ratio & 0.1068 & 0.0323 \\
\hline & & & $\mathrm{FEF}_{75}$ absolute & 0.09967 & 0.0458 \\
\hline \multirow[t]{7}{*}{ Nonresponders } & After treatment & Dyspnea vs. & $\mathrm{FEV}_{1} \%$ predicted & -0.2592 & $<0.0001$ \\
\hline & & & VC \%predicted & -0.2321 & $<0.0001$ \\
\hline & & & FVC \%predicted & -0.2484 & $<0.0001$ \\
\hline & & & PEF absolute & -0.1004 & 0.0441 \\
\hline & & & PEF \%predicted & -0.1995 & $<0.0001$ \\
\hline & & & $\mathrm{FEF}_{50} \%$ predicted & -0.1406 & 0.0047 \\
\hline & & & $\mathrm{FEF}_{25-75} \%$ predicted & -0.1406 & 0.0047 \\
\hline
\end{tabular}

Only spirometric parameters with significant coefficients are shown. 
Table 3 Correlations between changes $(\Delta)$ in asthma symptoms and changes in lung function parameters

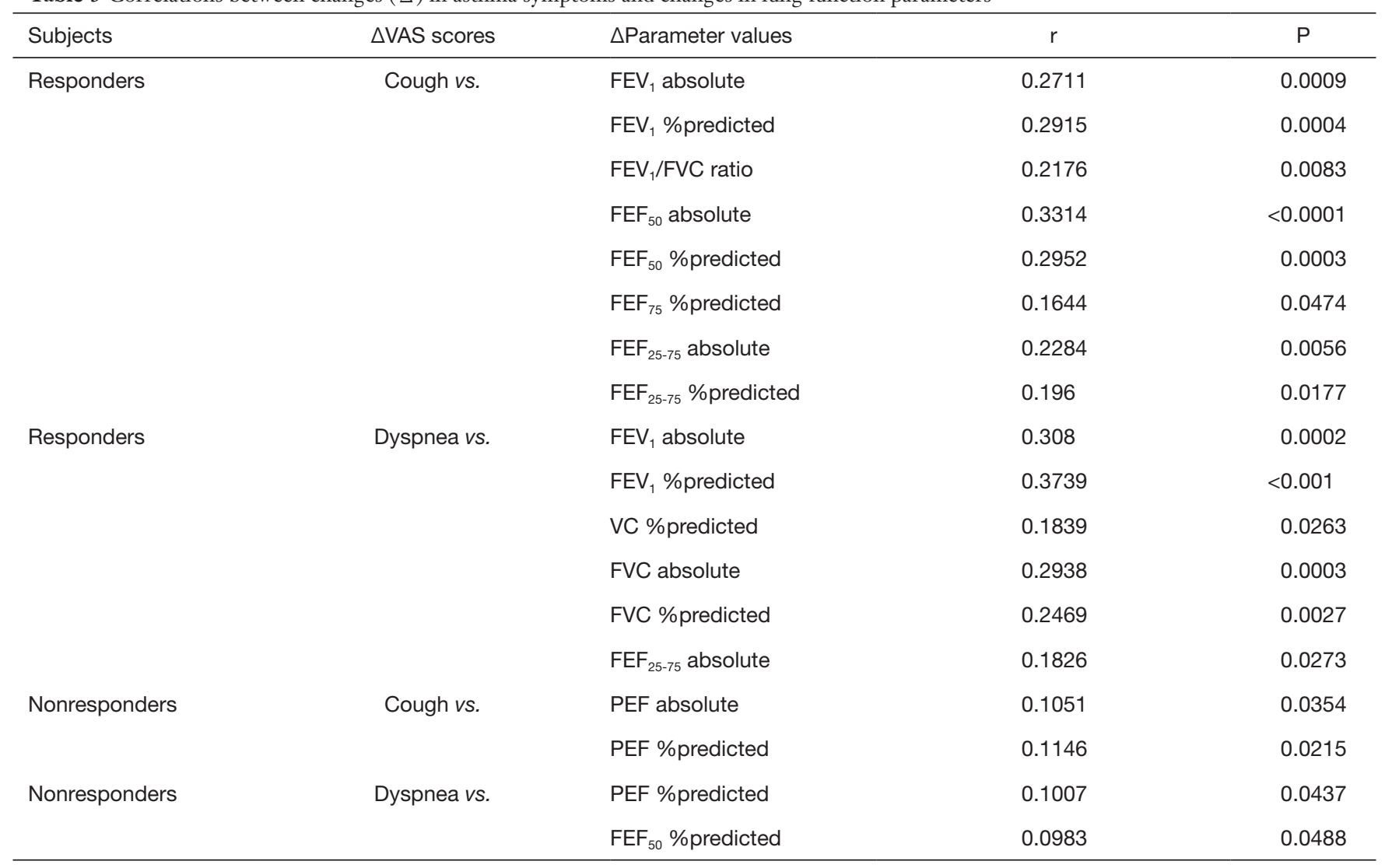

Only spirometric parameters with significant coefficients are shown.

cough after the treatment was only $8.7 \%$ in nonresponders with statistically similarity to responders. To explain from a different perspective, 134 (33.3\%) of 402 nonresponders did not improve $\mathrm{FEV}_{1}$ after the ICS/LABA treatment (data not shown). Among 134 patients, no improvement of dyspnea or cough was obtained in 41 and 33 patients, respectively (data not shown). Finally, 20 (5.0\%) of 134 patients who had no gain in $\mathrm{FEV}_{1}$ after the treatment had no improvement for both dyspnea and cough (data not shown). These observations suggested the nonresponders in our study were sufficiently reactive with the ICS/LABA treatment.

Cough was perceived to be more common than dyspnea in responders and nonresponders at baseline in our study population. Improvements of cough and dyspnea occurred in both groups after ICS/LABA treatment, but nonresponders recognized less improvement in cough compared to dyspnea. The severity of cough was similar in the two groups at baseline, but symptomatic improvement was greater in responders after treatment. These observations suggest that responders perceived more severe dyspnea at baseline and had more relief from dyspnea after treatment. Evaluation of changes in symptoms from baseline to after treatment revealed larger responses for cough and dyspnea in responders. These comparisons suggest that perceptions of cough and dyspnea were similar, but not identical, to each other, and that perceptions of symptoms were also similar, but not identical, in responders and nonresponders.

We also evaluated correlations of cough and dyspnea with measurements of pulmonary function. In responders, PEF (absolute, \% predicted) was significantly correlated with cough, and $\mathrm{FEV}_{1}$ (\% predicted), VC (\% predicted) and PEF (absolute) were significantly correlated with dyspnea both before and after treatment. In nonresponders, no spirometric parameter was significant correlated with cough or dyspnea both before and after treatment. Regarding changes in VAS scores from before to after treatment, in responders, $\triangle \mathrm{FEV}_{1}$ (absolute, \% predicted) and $\triangle \mathrm{FEF}_{25-75}$ (absolute) were significantly correlated with $\triangle \mathrm{VAS}$ for cough and dyspnea. In responders, changes of expiratory volume 
both at large airway and small airway levels contribute to improvement in perceptions. A change of $\mathrm{FEV}_{1}$ reflects direct bronchodilating responsiveness, and $\mathrm{FEF}_{25-75}$ may be a weak marker of control of asthma (22). Hence, this linkage of symptoms and particular spirometric parameters in responders is of interest and it remained to investigate in future to explain these linkages. In nonresponders, there were correlations of $\triangle \mathrm{VAS}$ scores for cough or dyspnea with $\triangle \mathrm{PEF}$ (\%predicted). These analyses suggest that both responders and nonresponders have linkages with certain spirometric parameters, but that these differ between the two groups.

We also analyzed perceptions of symptoms using linear regression. These analyses are frequently performed for bronchoconstrictive responses induced with agents such as methacholine, with the slope ( $\triangle \mathrm{VAS}$ score/ $\Delta \mathrm{FEV} \mathrm{V}_{1}$ ) calculated at various concentrations of methacholine inhaled by each patient (14-19). In the current study, an overall slope was calculated for each group, rather than for individuals. The slopes showed that perception of cough was not different between responders and nonresponders, but that of dyspnea did differ. In previous studies using this approach to evaluate responsiveness to bronchoconstrictive stimuli, the perception of dyspnea was less sensitive in patients with severe asthma (14), lower $\mathrm{FEV}_{1}(15)$, high bronchial responsiveness to histamine (15), and moderate to severe airway hyperresponsiveness (AHR) (19); and ICSs enhance perception of airway narrowing (17) and dyspnea (18). It is difficult to compare these studies, which were performed with bronchoconstrictive stimuli, with our study using bronchodilating stimuli, but the perception of dyspnea seems to differ between responders and nonresponders. There are also some limitations in our study, including that the patients may have had a peculiar or ordinary phenotype of adult asthma, and we did not consider symptoms such as phlegm, although all patients had symptoms of dyspnea or cough or both.

We note that the ACQ and ACT are effective for evaluation of asthma control, but perceptions of cough and dyspnea differed between symptoms before and after treatment, and in patients with and without bronchodilating responsiveness to ICS/LABA treatment. In addition, cough and dyspnea were correlated with some spirometric parameters, but without consistency between symptoms or patients with different bronchodilating responses. Therefore, a more precise understanding of each symptom and an independent evaluation of pulmonary function are necessary for more effective management of patients with bronchial asthma.

\section{Conclusions}

Cough and dyspnea are often encountered in patients with bronchial asthma, and improvement or deterioration of these symptoms is commonly judged collectively. However, in this study, perceptions of cough and dyspnea were not identical among bronchodilating responders and nonresponders. Spirometric parameters were correlated with the symptoms to some extent, but this was also inconsistent. We would recommend to use VAS scoring with spirometry at the same time or different time to evaluate the vague perception even when a patient is not being treated.

\section{Acknowledgments}

The authors are grateful to Ms. Yuri Kawamura for data collection and statistical analysis.

\section{Footnote}

Conflicts of Interest: The authors have no conflicts of interest to declare.

Ethical Statement: The authors are accountable for all aspects of the work in ensuring that questions related to the accuracy or integrity of any part of the work are appropriately investigated and resolved. This singlesite retrospective study was approved by the institutional review board of Ohwada Clinic (No. E1506-K05). Written informed consent was obtained from all patients or surrogates in accordance with the Declaration of Helsinki.

\section{References}

1. Schäper C, Gläser S, Obst A, et al. Symptoms and diagnosis of asthma in a general population - longitudinal results from the SHIP database. J Asthma 2010;47:860-4.

2. Niimi A, Ohbayashi $H$, Sagara $H$, et al. Cough variant and cough-predominant asthma are major causes of persistent cough: a multicenter study in Japan. J Asthma 2013;50:932-7.

3. Juniper EF, O'Byrne PM, Guyatt GH, et al. Development and validation of a questionnaire to measure asthma control. Eur Respir J 1999;14:902-7.

4. Nathan RA, Sorkness CA, Kosinski M, et al. Development 
of the asthma control test: a survey for assessing asthma control. J Allergy Clin Immunol 2004;113:59-65.

5. Available online: https://ginasthma.org/wp-content/ uploads/2019/01/2017-GINA.pdf. Page 26-34.

6. Manning HL, Schwartzstein RM. Respiratory sensations in asthma: physiological and clinical implications. J Asthma 2001;38:447-60.

7. Ohta K, Jean Bousquet P, Akiyama K, et al. Visual analog scale as a predictor of GINA-defined asthma control. The SACRA study in Japan. J Asthma 2013;50:514-21.

8. van Gent R, van Essen-Zandvliet LE, Rovers MM, et al. Poor perception of dyspnoea in children with undiagnosed asthma. Eur Respir J 2007;30:887-91.

9. Ohwada A, Inami K, Onuma E, et al. Bronchial reversibility with a short-acting $\beta 2$-agonist predicts the FEV1 response to administration of a long-acting $\beta 2$ agonist with inhaled corticosteroids in patients with bronchial asthma. Exp Ther Med 2011;2:619-23.

10. Kubota M, Kobayashi H, Quanjer PH, et al. Reference values for spirometry, including vital capacity, in Japanese adults calculated with the LMS method and compared with previous values. Respir Investig 2014;52:242-50.

11. Reference of values of Japanese spirometry and arterial blood analysis (in Japanese). Available online: www.jrs. or.jp/quicklink/journal/nopass_pdf/039050000j.pdf

12. Hankinson JL, Odencrantz JR, Fedan KB. Spirometric reference values from a sample of the general U.S. population. Am J Respir Crit Care Med 1999;159:179-87.

13. Available online: https://ginasthma.org/wp-content/ uploads/2019/01/2017-GINA.pdf. Page 14-23.

14. Veen JC, Smits HH, Ravensberg AJ, et al. Impaired perception of dyspnea in patients with severe asthma. Relation to sputum eosinophils. Am J Respir Crit Care

Cite this article as: Ohwada A, Sato K. Heterogeneity of perception of symptoms in patients with asthma. J Thorac Dis 2019;11(12):5218-5227. doi: 10.21037/jtd.2019.11.72
Med 1998;158:1134-41.

15. Bijl-Hofland ID, Cloosterman SG, Folgering HT, et al. Relation of the perception of airway obstruction to the severity of asthma. Thorax 1999;54:15-9.

16. Couillard S, Bougault V, Turmel J, et al. Perception of bronchoconstriction following methacholine and eucapnic voluntary hyperpnea challenges in elite athletes. Chest 2014;145:794-802.

17. Salome CM, Reddel HK, Ware SI, et al. Effect of budesonide on the perception of induced airway narrowing in subjects with asthma. Am J Respir Crit Care Med 2002;165:15-21.

18. Roisman GL, Peiffer C, Lacronique JG, et al. Perception of bronchial obstruction in asthmatic patients. Relationship with bronchial eosinophilic inflammation and epithelial damage and effect of corticosteroid treatment. J Clin Invest 1995;96:12-21.

19. Koh YI, Choi IS, Lim H. Airway responsiveness as a direct factor contributing to the dyspnoea perception in asthma. Respir Med 2001;95:464-70.

20. Ichinose M, Sugiura H, Nagase H, et al. Japanese guidelines for adult asthma 2017. Available online: https://www.allergologyinternational.com/article/S13238930(16)30174-5/pdf

21. Yancey SW, Ortega HG. Retrospective characterization of airway reversibility in patients with asthma responsive to bronchodilators. Curr Med Res Opin 2007;23:3205-7.

22. Kanchongkittiphon W, Gaffin JM, Kopel L, et al. Association of FEF25\%-75\% and bronchodilator reversibility with asthma control and asthma morbidity in inner-city children with asthma. Ann Allergy Asthma Immunol 2016;117:97-9. 